\title{
Professores das primeiras séries do ensino fundamental e relações estabelecidas com o conhecimento ${ }^{1}$
}

\section{Teachers of the first grades of elementary education and the relations established with knowledge}

\author{
Marieta Gouvêa de Oliveira Penna ${ }^{2}$
}

\begin{abstract}
RESUMO
Este artigo apresenta análise realizada sobre as relações estabelecidas pelo professor com o conhecimento no exercício da docência, nas séries iniciais do ensino fundamental em escolas públicas. Foi possível verificar que as professoras entrevistadas estabelecem relação utilitária e superficial, seja com o conhecimento científico, seja com o conhecimento das disciplinas escolares, em decorrência de aprendizado ocorrido nos momentos de formação inicial ou de formação continuada e referido à sua aplicabilidade prática, bem como daquilo que o exercício docente proporciona e exige dos professores em sua lida cotidiana. Além disso, destaca-se a valorização de conhecimento adquirido com a experiência.

Palavras-chave: exercício docente; formação de professores; saberes docentes; conhecimento.
\end{abstract}

\footnotetext{
ABSTRACT

This paper presents an analysis conducted on the relationship established by the teacher with knowledge in the teaching activity, in the initial grades of elementary education in public schools. It was possible to verify that the interviewed teachers establish a utilitarian and superficial relationship,

${ }^{1}$ Financiamento do Conselho Nacional de Desenvolvimento Científico e Tecnológico (CNPq).

${ }^{2}$ Doutora em Educação pela Pontifícia Universidade Católica (PUC/SP), Professora da Universidade Federal de São Paulo (USP), Brasil. E-mail: marieta.penna@unifesp.br.
} 
either with scientific knowledge or with the knowledge on school subjects. This type of relationship is caused by the kind of learning developed in moments of initial or continued formation and related to its practical applicability, as well as by what the teaching activity provides and demands from the teachers in their daily work. Moreover, the valorizing of knowledge acquired with the experience is highlighted.

Keywords: teaching activity; teachers' formation; teachers' knowledge; knowledge.

\section{Introdução}

O objetivo neste artigo é apresentar reflexões sobre o exercício da docência no que diz respeito a aspectos das relações estabelecidas pelos professores com o conhecimento no exercício dessa função. Trata-se de análises realizadas sobre o exercício docente nas primeiras séries do ensino fundamental em escolas públicas do Estado de São Paulo, com o objetivo de compreender qual a relação com o conhecimento que esse exercício favorece e exige dos agentes que a ele se dedicam. Os dados analisados foram coletados por meio de entrevistas semiestruturadas com dez professores das séries iniciais do ensino fundamental. A escolha dos professores levou em consideração a série em que atuavam, ou seja, em cada uma das escolas foi selecionada uma professora de cada uma das quatro séries do ensino fundamental, perfazendo um total de oito sujeitos. A escolha das escolas se deu priorizando sua localização, uma em bairro periférico e outra em bairro mais central da cidade. Além disso, mais dois professores que não estavam vinculados às escolas foram entrevistados, a fim de se evitar possível efeito de seleção, uma vez que nas duas escolas a equipe gestora influenciou na determinação de quais professores participariam da pesquisa.

As análises realizadas, por um lado, dizem respeito à compreensão da escola como instituição que porta cultura específica, constituída historicamente. De acordo com Julia (2001), as práticas e normas realizadas na escola compõem a cultura escolar e dizem respeito ao seu funcionamento interno, cujas finalidades variam historicamente. O professor, ao se socializar no e para o exercício da função docente, encontra-se imerso na cultura escolar. Por outro lado, dizem respeito à compreensão do trabalho do professor informado por diferentes saberes. Tardif (2002), ao investigar os saberes mobilizados pelos professores em sua prática cotidiana, aponta esses saberes como provenientes de diferentes lugares, entre os quais se destaca a experiência no exercício da função docente. 


\section{As professoras entrevistadas}

Todos os professores entrevistados para esta pesquisa eram mulheres, uma vez que nas escolas em que foram realizadas as entrevistas não existiam professores do sexo masculino lecionando. Essa informação é relevante para o que aqui se analisa, uma vez que as relações estabelecidas socialmente são marcadas por questões de gênero. De acordo com Catani et al. (1997), a docência nas séries iniciais da escolarização, função feminina, é área de atuação destinada a preservar as mulheres de contato mais produtivo com o conhecimento científico, em que se verifica nos momentos de formação a imposição acrítica de teorias psicológicas traduzidas em práticas pedagógicas.

A feminização do magistério contribuiu de forma decisiva para estabelecer o lugar destinado ao conhecimento científico nos cursos de formação de professores. Ao se tornar atividade feminina, a docência perdeu atributos intelectuais do mestre e agregou atributos femininos, como cuidar de crianças (LOURO, 1997). Com relação a essa questão, Demartine e Antunes (2002) destacam distinção existente entre a formação de meninos e meninas no início do século XX, revelando representação da mulher como menos capacitada que os homens para determinados assuntos intelectuais.

Já nos cursos de formação para professores, Pereira (1969) indica que, apesar dos esforços traçados na década de 1930 para melhorá-los e torná-los mais profissionalizantes, a ênfase dada à formação da mulher como mãe e professora permaneceu, reduzindo a formação fornecida às futuras professoras em seus aspectos técnicos relacionados ao exercício docente e ressaltando características pessoais associadas à feminilidade.

O exercício docente nas primeiras séries da escolarização visto como assunto de mulheres, relacionado a características socialmente tidas como femininas, como, por exemplo, a paciência e a docilidade, ainda hoje se faz presente nas representações sociais dos professores. Observa-se que é considerado atributo feminino preocupar-se mais com o emocional que com questões relacionadas ao intelecto. Assim, a mulher se vê socialmente destinada a funções em que se supõe não precisar pensar e que exigem qualificação banal ou facilmente adquirível, como serviços de escritório, recepcionistas, serviços relacionados à saúde e educação, sempre nas posições mais desqualificadas (APPLE, 1995).

Essas questões compõem tanto a forma como a mulher se vê em relação ao conhecimento e possibilidades de apropriação deste, bem como o próprio exercício da função docente. Para ser professor não precisa muita coisa, basta possuir atributos socialmente considerados femininos, como paciência e amor. 
Por se tratar do ensino de crianças, precisa menos ainda, ainda mais quando é o caso de crianças vindas das camadas mais desfavorecidas da população.

Ainda com relação aos sujeitos da pesquisa, no que se refere à formação das professoras, todas concluíram o magistério, sendo que três o fizeram em escolas particulares e sete em escolas públicas. No que diz respeito à formação em nível superior, apenas metade delas chegou a esse nível de ensino, sendo que duas fizeram Pedagogia, uma fez Matemática e duas estavam cursando Pedagogia quando da realização das entrevistas, todas em instituições privadas. $\mathrm{Na}$ época em que as professoras entrevistadas optaram por exercer a docência, não era necessária formação em nível superior, a não ser para ocupar o cargo de direção. Dessa forma, a docência se apresentou como opção de profissionalização que requeria a opção pelo curso normal após a conclusão do ginásio, ou, posteriormente, de acordo com a Lei 5.692/71, a conclusão do segundo grau na Habilitação Específica para o Magistério (HEM). Todas observaram que os pais não tinham condições de arcar com as despesas da faculdade, caso resolvessem cursá-la. Assim, fazer curso superior não estava entre os planos de seus pais, que se contentavam com a formação de suas filhas como professoras, em nível médio, estabelecendo estratégia de escolarização com objetivo de profissionalização.

Algumas delas consideraram como suficiente atingir apenas essa formação, como foi o caso de Clara $^{3}$ e Maria Cecília. Para outras, a possibilidade e, portanto, o desejo de fazer faculdade surgiram após o ingresso na docência, como foi o caso de Isaura e Paula, ou de Mariana. Mesmo trabalhando como professora, a realização desse sonho ainda não foi possível para Fátima. Já Laura e Helena afirmaram que não estudaram em decorrência de impedimentos traçados por seus maridos, expressando relações marcadas pela questão de gênero. Marli e Diva escolheram a Pedagogia como estratégia para melhorar de vida e pagaram seus estudos trabalhando como doméstica ou mesmo como balconista.

De qualquer forma, todas elas advêm de famílias que valorizavam a escolarização como a melhor forma de mudar a condição de vida dos filhos, apostando na forma de incentivos, mesmo que essa escolarização não representasse atingir seus níveis mais elevados ou socialmente considerados como de maior prestígio. Em suas famílias, a escola se destacou claramente como estratégia de mobilidade social, do que pode decorrer relação utilitária com o conhecimento. Ou seja, para elas estudar, antes de ter sentido formativo, relacionado à ampliação de conhecimentos, tinha sentido atribuído a um objetivo pragmático.

Além do que foi acima discutido, a fim de se questionar a relação estabelecida pelas professoras entrevistadas com o conhecimento, é possível também

\footnotetext{
${ }^{3}$ Os nomes das professoras são fictícios.
} 
levantar questões relativas à sua formação escolar, provavelmente ocorrida em condições precárias, em estabelecimentos públicos até o término do ensino médio e em instituições privadas quando diz respeito ao nível superior.

\section{Aspectos da formação de professores e de sua prática pedagógica}

Para se questionar qual a relação estabelecida pelo professor com o conhecimento em decorrência do exercício, é fundamental atentar para aspectos relacionados à formação de professores na atualidade. Segundo Nóvoa (1995a), a formação docente na atualidade - seja ela inicial ou continuada - articula-se em torno de três eixos, quais sejam: aspectos relacionados à ciência da educação, aspectos metodológicos e aspectos relacionados aos conteúdos escolares.

Com relação ao primeiro eixo, Popkewitz (1995) argumenta que a formação dos professores diz respeito à aquisição fragmentada de informações e competências dirigidas à prática, deixando de lado orientações intelectuais, fato que se acirra na atualidade. Para o autor, a pedagogia, ao legitimar a organização do currículo e debruçar-se sobre questões relacionadas à aprendizagem, contribuiu para racionalizar o trabalho do professor e consolidá-lo como atividade técnica, valorizando o conhecimento empírico e funcional, além de propiciar a sua regulação e o seu controle. Dessa forma, a pedagogia seleciona, organiza e avalia o conhecimento destinado aos professores, mas escapa da tarefa de fornecer as bases teóricas que sustentem esse conhecimento. Nessa mesma direção, Nóvoa (1995a) destaca o baixo nível em relação à formação científica exigida dos professores, que para ele diz respeito ao controle ideológico exercido especialmente da parte do Estado, responsável por essa formação. Catani et al. (1997), ao analisarem os cursos de formação docente, tanto em nível médio como na Pedagogia, no que se refere ao aprendizado de teorias educacionais, apontam essa formação como oposta à formação intelectual, espaço de aprendizagem reservado ao secundário, de caráter propedêutico, e aos demais cursos superiores. Para as autoras, os cursos de formação para professores despontam como opostos ao conhecimento científico, apresentando conhecimento infantilizado e mediado por sua aplicação prática.

O discurso pedagógico, por ser prescritivo e impor modelo de atuação, traduz e simplifica a teoria. Dessa forma a educação padece de mal-estar estrutural em relação ao conhecimento científico, cujo acesso irrestrito é negado aos educadores. A área expressa dificuldades em relacionar a teoria (de cunho interpretativo) à prática (de cunho prescritivo) ao não preservar a natureza distinta 
dessas operações. Essa cisão se expressa, por exemplo, na dissociação existente entre o bacharelado e a licenciatura, limite preestabelecido ao conhecimento e à capacidade de conhecer.

O segundo aspecto apontado por Nóvoa (1995a), relacionado à formação dos professores, diz respeito às metodologias de ensino, ou seja, à necessidade de se aprender como ensinar. No processo histórico da constituição da função de professor na modernidade, Nóvoa (1995b) aponta que o ensino, ao se destacar como ocupação secundária de religiosos de algumas congregações como, por exemplo, dos jesuítas e dos oratorianos, trouxe em seu bojo a formulação de um conjunto de técnicas organizadas em torno de estratégias de ensino, além de um sistema normativo de atitudes e competências desejadas àqueles que se dedicassem ao desempenho dessa função. Nos cursos de formação de professores, algumas disciplinas se dedicam ao ensino de metodologias. Ao analisar processos formativos direcionados aos professores, Azanha (2006) destaca o caráter prescritivo e salvacionista neles implicado, nos quais novas propostas metodológicas são apresentadas em tom de convencimento e com o suposto de trazerem a solução para os problemas relacionados ao ensino.

Além disso, essas técnicas ou modos de ensinar compõem a cultura escolar (JULIA, 2001). A cultura escolar "consagra modos específicos de lidar com a vida escolar e as situações de ensino" (CATANI, 1994, p. 17). Aprende-se a ser professor em parte pela adoção de comportamentos relacionados à conduta do bom professor. Diferentes autores, ao analisarem aspectos da prática educativa realizada pelos professores, apontam elementos para a compreensão das aprendizagens por eles efetuadas no exercício de sua função. Para Gimeno Sacristán (1995), essa prática educativa se apoia mais em saberes da experiência, oriundos da cultura escolar, que em conhecimento advindo dos momentos de formação. Nesse sentido, Marcelo García (1991) analisa a aprendizagem realizada pela socialização dos professores no ambiente escolar, em que os docentes aprendem a ensinar ao interiorizar normas, valores e condutas relacionados ao exercício da função, por meio do contato estabelecido com os colegas e com a instituição.

O terceiro aspecto destacado por Nóvoa (1995a) e relacionado à formação dos professores diz respeito aos conteúdos das diferentes disciplinas ensinadas na escola (história, geografia, matemática, entre outras), que não guardam relação direta com o conhecimento científico, mas são elaborados para serem ensinados, conforme atestam os estudos de Chervel (1990) e Goodson (1990), entre outros. Além disso, convém destacar que a elaboração dos conteúdos escolares pressupõe seleção em relação ao legado cultural acumulado pela humanidade. Dessa forma, o conhecimento escolar diz respeito a conteúdos selecionados e que, a fim de possibilitar sua transmissão, são elaborados didaticamente e 
hierarquizados (FORQUIN, 1992). Ao pôr em discussão a seleção realizada pela escola em relação ao que nela é transmitido, Bourdieu e Passeron (1982) destacam o fato de essa instituição operar um duplo arbitrário, uma vez que inculca arbitrário cultural cujo conteúdo foi arbitrariamente selecionado. Para os autores, a seleção e a elaboração do conhecimento escolar dizem respeito a necessidades sociais, ou seja, esse conhecimento é produzido na e para a escola, mas não é autônomo e relaciona-se a determinantes mais amplos. O sistema de ensino possui, no entanto, autonomia relativa, o que garante sua especificidade, que se relaciona à forma escolar de transmissão. Os professores têm por tarefa transmitir o conhecimento escolar. Em sua prática, em decorrência de questões relacionadas à função que exercem e aos determinantes objetivos de sua realização, estabelecem relação com o conhecimento escolar, por meio de livros didáticos e apostilas, sendo que, muitas vezes, nem mesmo com esse conhecimento possuem familiaridade.

Conforme destacado, em sua formação os professores têm contato com aspectos do conhecimento científico produzido em educação, que é parcial, pois é previamente filtrado e adaptado para utilização prática na sala de aula. Além disso, possuem saberes práticos a serem aprendidos, sobre os quais, sem a possibilidade de compreensão mais ampliada em relação aos fins da educação e seus determinantes sociais, não estabelecem mediação. Entram também em contato com o conhecimento das disciplinas escolares, em relação ao qual, em decorrência de deficiências em sua formação, têm dificuldade em se apropriar.

De acordo com Tardif e Raymond (2000), o trabalho do professor efetiva-se na sala de aula, no contato com os alunos, a quem direcionam o seu fazer, envolvendo uma série de tarefas anteriores e posteriores a esse contato, como orientar os estudos, ajudar os alunos, regular relações, preparo de materiais, seleção de atividades, organização do espaço. Para tanto, o professor mobiliza saberes adquiridos pela experiência, por processos de formação e com o contato com os colegas. O professor toma decisões em função de julgamentos profissionais que não se limitam a fatos, baseando-se em valores morais, normas sociais, tradições escolares e experiência vivida. Assim, cabe questionar em que condições o professor estabelece mediações com esse conhecimento que adquire com a experiência de trabalho, ou seja, o professor é capaz de refletir sobre essa experiência compartilhada nos momentos de socialização profissional, a fim de dela se apropriar de forma crítica, ou apenas reproduz tradições relacionadas à cultura escolar e seus modos consagrados de atuação? 


\section{As professoras e a relação com o conhecimento}

Nas entrevistas realizadas para a elaboração da pesquisa aqui apresentada, foi possível destacar alguns aspectos relevantes para a compreensão da relação estabelecida pelas professoras com o conhecimento no exercício da função docente que, por sua vez, expressam a relação por elas estabelecida com o conhecimento nos momentos de formação e socialização profissional. No que diz respeito à formação inicial, as professoras, ao relatarem como percebiam a importância dessa formação por elas recebida, no que diz respeito à condução de sua prática cotidiana, afirmaram que possuir uma boa formação inicial não era o requisito mais importante a fim de realizar-se a docência de forma adequada, uma vez que o mais importante para ser um bom professor era, sobretudo, ter boa vontade e vocação para o trato com os alunos, expressando aspectos das relações de gênero socialmente estabelecidas e destacadas anteriormente:

Eu acho que para ser professor precisa muita boa vontade. Mas a formação também é importante, se não a gente acaba se acomodando. Acho bom agora exigir a pedagogia, eu aprendi muita coisa quando fiz o magistério. (Maria Cecília).

Além disso, para elas, era difícil relacionar o que aprenderam nos cursos de formação inicial ao que vivenciavam em suas práticas na sala de aula, apontando a velha cisão estabelecida entre teoria e prática no que diz respeito à prática educativa escolar. Conforme apontado anteriormente, a formação inicial oferecida aos professores apresenta dificuldades em relacionar a teoria (de cunho interpretativo) à prática (de cunho prescritivo), ao não preservar a natureza distinta dessas operações. Além disso, destaca-se que, conforme discutido por Santomé (1996), o professor vivencia a teoria como ameaça, uma vez que diz respeito a um grupo de pessoas estranhas que se consideram especialistas em assuntos educacionais, com legitimidade para gerar conhecimento válido sobre suas práticas educativas. A teoria educacional é disponibilizada aos professores como verdade e não como leitura de mundo. Nesse sentido, a questão teórica necessita ser redimensionada, não no sentido de traduções práticas, aos moldes de algumas concepções psicológicas, mas em seu sentido mais profundo, ou seja, de compreensão da realidade objetiva.

Some-se a isso o fato de que, ao tecerem considerações sobre a formação necessária ao exercício da docência, para elas, o mais importante era que essa 
formação fornecesse elementos para o futuro professor enfrentar os problemas práticos relacionados ao cotidiano, o que nem sempre ocorria na formação inicial. Assim, para elas, a formação inicial não oferece elementos suficientes para informar a atuação docente e é só com a prática que o professor aprende a trabalhar. A formação inicial só tem sentido se informar essa prática, restringindo-se a seus aspectos técnicos. Por isso, valorizavam mais os cursos de formação continuada, que de seu ponto de vista são mais úteis, uma vez que contêm informações que as auxiliavam na resolução de problemas ligados à sua prática cotidiana. Mesmo reconhecendo certa importância da formação inicial para o exercício docente ou a necessidade de o professor participar de cursos de formação continuada, o que realmente importava para elas era a formação adquirida com a prática, por meio do contato com os colegas e do enfrentamento dos problemas em seu dia a dia:

Fazendo a faculdade eu adquiri muito conhecimento. Na parte pedagógica, na área de conhecimento técnico, melhorou muito. Conheci outros autores, teorias de psicologia... O ideal é o professor ter curso superior, faz diferença. [...] Mas é muito difícil a gente ver uma escola funcionar do jeito que a gente aprende na faculdade. São coisas muito distantes. (Marli).

Eu achei que foi importante para mim fazer a faculdade, mas eu fui aprender a dar aula mesmo foi na prática, foi na sala de aula. (Diva).

Aprende-se de fato a ser professor por meio do exercício prático da docência, destacando aspectos do conhecimento da experiência referidos por Tardif et al. (1991). No entanto, mesmo com a valorização, por parte das professoras, do conhecimento adquirido por elas em sua prática cotidiana, foi possível verificar nas entrevistas realizadas a existência de angústias e incertezas sobre esse patrimônio que possuíam, em decorrência das reformas realizadas nas últimas décadas e que entraram nas salas de aula impondo modificações na forma como até então trabalhavam. As professoras citaram, por exemplo, a adoção do construtivismo nas escolas, ao qual tiveram que se adaptar mesmo sem receber preparo para tal, ou mesmo da progressão continuada, que também não compreendiam.

Assim, verifica-se que essas mudanças introduzidas na escola abalaram as certezas das professoras, ao mesmo tempo em que não foram capazes de provocar alterações positivas tendo por base a apropriação de novos conhe- 
cimentos. Caberia investigação mais aprofundada sobre essa questão, mas os indícios presentes nos depoimentos das professoras apontaram para a escola como um ambiente confuso, em que as professoras sentiam-se inseguras, uma vez que o que anteriormente faziam não poderia mais ser feito, ao mesmo tempo em que não foram ensinadas a elas, de forma consistente, as novas práticas a serem efetivadas. Além disso, as professoras não possuíam formação que lhes possibilitasse autonomia para refletir e compreender essas mudanças, ficando dessa forma nas mãos de formadores que não lhes inspiravam confiança.

Sobre a efetivação do currículo em sala de aula, no que diz respeito a inovações introduzidas nas práticas pedagógicas a partir de reformas governamentais, Sampaio e Marin (2004) apresentam reflexões estimulantes, relacionando o esvaziamento da função cultural da escola às precariedades existentes nas condições de trabalho do professor (dentre as quais a formação se destaca), que por sua vez são socialmente estabelecidas. Goller (2002), em pesquisa realizada sobre a prática de professoras nas séries iniciais do ensino fundamental, destacou a existência de precariedades na formação das professoras, expressas na distância existente entre orientações e diretrizes curriculares estabelecidas oficialmente e a prática realizada em sala de aula, uma vez que as professoras não as compreendem. Destacou também o recebimento de informações distorcidas e fragmentadas pelas professoras no que diz respeito às teorias educacionais que fundamentam tais orientações e diretrizes curriculares, informadas por técnicos e capacitadores que também não as compreendem. Além disso, destacou resistências por parte das professoras em aderir ao novo, que ameaçava práticas estabelecidas e com as quais se sentiam seguras.

De acordo com Viñao-Frago (2000), a compreensão da distância existente entre reformas educacionais e sua efetivação pelos professores nas escolas implica análise da escola como portadora de cultura historicamente instituída, bem como da rede de relações estabelecidas no exercício docente. As professoras por mim investigadas, além de expressarem dificuldades para compreender e realizar as novas orientações recebidas, adaptavam o novo ao que já sabiam fazer, o que mais uma vez demonstra a força das aprendizagens sedimentadas em decorrência da experiência prática, expressando aspectos da cultura escolar. Dessa forma, verifica-se que permanecem na escola antagonismos entre o "velho" e o "novo", o "tradicional" e o "moderno", sem que isso favoreça às professoras a possibilidade de reflexão sobre suas práticas, promovendo muito mais a adaptação às novas práticas exigidas e a sua readequação pelas professoras, em condições precárias de trabalho e de esvaziamento das funções culturais da escola. Aprendem na prática, mas numa prática que teve algumas de suas certezas abaladas, sem a possibilidade de reflexão por parte das professoras sobre essas modificações. 


\section{As professoras e os estudos}

No que diz respeito ao exercício docente e à necessidade de se estudar a fim de concretizarem sua ação cotidiana e assim enfrentar as exigências que lhe são feitas, todas as professoras entrevistadas afirmaram que a função exige que estudem. Esses estudos, no entanto, pelo que foi indicado em seus depoimentos, eram realizados com finalidades bastante específicas. As professoras estudavam porque precisavam se atualizar, a fim de estarem aptas a lecionar e atender às expectativas de seus alunos. Para elas, o professor precisa ler para se manter atualizado em termos de assuntos gerais e de interesse dos alunos.

Além da necessidade de se atualizarem para enfrentar as demandas apresentadas por seus alunos, deveriam ler sempre a fim de servir de modelo para eles e poder ensiná-los a ler. Deveriam também possuir o hábito de leitura a fim de se diferençar de seus alunos, que eram preguiçosos e não gostavam de ler. Some-se a isso o fato de que necessitavam se distinguir das demais pessoas com quem conviviam socialmente, pois, afinal, eram professoras:

O professor precisa estar inteirado de todos os assuntos. Por que, como é que ele vai ser professor se ele não estiver sabendo de qualquer assunto que estiver sendo discutido em qualquer lugar? Como é que fica? Fica mal para ele, como professor. [...] Se você está numa roda entre amigos, por exemplo, na sociedade, no nosso país, a gente tem que estar sempre atualizado. Surge um assunto, você não sabe o que falar sobre ele, como é que fica a nossa postura de professor?Vão dizer: "Que professora é essa que não sabe de nada, não sabe nem discutir? Puxa, e é professora!” As pessoas falam muito mesmo, a gente é muito fiscalizada, muito cobrada por ser professor. (Maria Cecília).

Dessa forma, os estudos aos quais as professoras se referiam como necessários para sua prática cotidiana diziam respeito à necessidade de se manterem atualizadas sobre assuntos de conhecimento geral, em que suas leituras eram realizadas com fins utilitários e distintivos. As professoras entrevistadas afirmaram realizar pesquisas para preparar suas aulas, para o que consultavam revistas, internet, apostilas, confeccionavam pastas de atividades e utilizavam fotocópias ou mesmo o mimeógrafo. Pelo que se verificou, os estudos e as pesquisas realizados pelas professoras restringiam-se à busca de atividades atuais e interessantes para oferecer aos alunos, a fim de renovarem as atividades que 
costumavam dar e assim estimular a participação dos alunos. Saber "como ensinar" os alunos destacou-se como mais importante do que saber "o que ensinar", ou seja, que dominar o conteúdo das disciplinas escolares.

A necessidade de estudar para aprender ou aprofundar aspectos do conteúdo das disciplinas escolares não foi mencionado uma única vez. Conhecer teorias educacionais sequer se apresentava em seus horizontes de possibilidade, com as professoras preocupando-se no máximo em ler alguma novidade sobre como aplicar métodos na sala de aula. Para elas, era preciso saber motivar os alunos, saber de assuntos atuais a fim de prender a atenção, pô-los para trabalhar e, sobretudo, manter a disciplina. As pesquisas que faziam recheavam suas aulas e, para saber como transformá-las em atividades interessantes para os alunos, elas observavam os professores mais experientes, pegavam ideias contidas em apostilas, pediam ajuda, até que "pegavam o jeito". Laura afirmou que com o tempo você "pega o jeito" e não precisa mais preparar as aulas, já sabe o que fazer, bastando trazer coisas atuais e novidades para os alunos. Quando interrogadas sobre a utilização de livros didáticos, todas afirmaram receber livros do governo, o que as auxiliava na seleção dos conteúdos que deveriam ensinar aos alunos, o que, ao que tudo indica, era a maneira como entravam em contato com o conteúdo das disciplinas escolares.

Assim, tanto a seleção das leituras que realizavam em decorrência do exercício docente (para se atualizar) como os cursos de formação continuada que faziam (para melhorar a prática), ou mesmo as pesquisas necessárias para o preparo das aulas (assuntos atuais e de interesse dos alunos), demonstraram que a função docente exige e proporciona relação utilitária com o conhecimento e preocupação acentuada muito mais com a forma que com o conteúdo, como expressa o depoimento de Fátima:

Porque eu vi a necessidade de eu buscar. Ainda mais que eu não tenho uma faculdade, que abriria muito a minha mente. Então eu comecei a buscar por mim mesma, revistas, livros, que eu via que me interessavam na questão da alfabetização, da disciplina dos alunos, eu sempre busquei ler. [...] Se você não se atualiza, você fica muito atrasada. Precisa motivar esses alunos, prender a atenção deles.

As professoras afirmaram não frequentar bibliotecas, seja para estudar ou preparar suas aulas na atualidade, seja na época em que eram alunas, mesmo as que fizeram curso superior. As leituras solicitadas por seus professores quando frequentaram a faculdade eram feitas em fotocópias ou em apostilas fornecidas por eles: 
Não, na biblioteca da faculdade, para falar a verdade, a gente não ia muito não. A gente lia muito, mas eram trabalhos com revistas, com apostilas, essas coisas. Mas ir ler livro na biblioteca a gente não ia muito não. (Diva).

Ao serem interrogadas sobre os hábitos de leitura que possuíam em suas vidas e o tipo de leitura que realizavam, a maioria delas afirmou gostar de ler e o fazer com frequência. A única que estava lendo no momento das entrevistas, no entanto, era Paula, que lia um livro religioso. Apenas Clara e Isaura afirmaram não gostar de ler, apesar de Isaura ponderar que, por necessidade, acabou por desenvolver esse hábito, a partir do momento em que fez o curso do magistério. Fátima, Lívia e Helena afirmaram ter desenvolvido o hábito de leitura desde a infância, incentivadas por seus pais e familiares. De qualquer forma, consideravam que a docência exigia que lessem muito, a fim de se manterem atualizadas, desenvolvendo ainda mais esse hábito que vinha da família. Já as outras, com exceção de Clara, que afirmou não possuir o hábito de leitura, relacionaram o desenvolvimento desse hábito em suas vidas diretamente ao fato de se tornarem professoras. Mesmo Diva, que quando era mocinha era sócia do Círculo do Livro, apontou que hoje em dia lê mais, apesar de serem leituras direcionadas às necessidades apresentadas pelo exercício docente, como se atualizar ou dar conta de alguma questão relacionada à aprendizagem dos alunos.

\section{Considerações finais}

Com a realização da pesquisa, a relação estabelecida pelas professoras com o universo do conhecimento científico e escolar pôde ser analisada em alguns aspectos. Verificou-se que as professoras estabeleciam relação utilitária e superficial com o conhecimento científico, quando era o caso, em decorrência de aprendizado ocorrido nos momentos de formação inicial ou de formação continuada e referido à sua aplicabilidade prática, bem como daquilo que o exercício docente proporciona e exige dos professores em sua lida cotidiana.

Além disso, nenhuma delas demonstrou preocupação com a necessidade de se apropriar do conhecimento das disciplinas escolares como, por exemplo, de História ou Matemática, que deveriam ensinar a seus alunos, e do qual se apropriavam apenas com a utilização de livros didáticos. Seus estudos e pesquisas, necessários para o preparo das aulas, se concentravam em atualidades gerais a fim de preparar aulas interessantes e assim motivar os alunos (informadas por 
revistas como Veja ou Época) ou na consulta a revistas como a Nova Escola, na tentativa de melhor compreender as questões disciplinares que as preocupavam.

Dentre os eixos estabelecidos por Nóvoa (1995a) e anteriormente referidos, as professoras de fato realizavam apenas o aprendizado de práticas escolares, seja nos momentos de formação inicial, de formação continuada e, especialmente, quando da imersão no ambiente escolar, por meio da socialização.

No que diz respeito às relações estabelecidas pelas professoras com o universo do conhecimento em decorrência do exercício docente, é importante ressaltar que, seja com relação à formação inicial ou continuada, seja em decorrência de aspectos do exercício mesmo da função, a docência nas primeiras séries da escolarização em escolas públicas não exige e não proporciona às professoras apropriação de conhecimentos científicos relacionados à área da educação e nem de conhecimentos relacionados às disciplinas escolares.

As professoras afirmaram se apropriar apenas de conhecimentos práticos relacionados ao exercício da função, aprendidos especialmente no contato com os colegas.

Dessa forma, verificou-se que os professores aprendem boa parte dos saberes que utilizam no desempenho da docência no contato com seus colegas e com aspectos da cultura escolar. Isso ocorre em situação em que não se exige das professoras, seja nos momentos de formação inicial, seja nos momentos de formação continuada, maior profundidade no que diz respeito a aportes teóricos que permitam a elas estabelecer reflexões sobre essa prática, na qual se veem imersas, sem a possibilidade do estabelecimento de mediações.

Assim, os professores, como afirmam Tardif et al. (1991), de fato aprendem aspectos importantes de sua função ao se verem imersos em sua lida cotidiana, acumulando patrimônio a ela relacionado. No entanto, por um lado, esse patrimônio necessita ser valorizado e compartilhado, no sentido de valorização dos professores e das boas práticas aprendidas com a experiência. Por outro lado, sem o estabelecimento de mediações e reflexões sobre as aprendizagens efetuadas pela socialização profissional, os professores seguem reproduzindo crenças, padrões e modelos de conduta que necessitam ser confrontados, na busca pela realização de um ensino mais democrático.

Além disso, cabe destacar que, ao se considerar o campo educacional, em que a posse de conhecimentos legítimos é fator de distinção, verifica-se que a posição ocupada pelos professores do primeiro segmento do ensino fundamental é desprestigiada, o que demonstra relação precária a eles exigida e propiciada em decorrência do exercício dessa função, ou seja, relação utilitária e permeada por sua aplicação prática, em que a apropriação de conhecimentos teóricos relacionados à educação ou mesmo às áreas do conhecimento científico não fazem parte de seu universo de possibilidades. 


\section{REFERÊNCIAS}

APPLE, Michael. W. Magistério e "trabalho feminino". In: Trabalho docente e textos: economia política das relações de classe e de gênero em educação. Porto Alegre: Artes Médicas, 1995, p. 53-73.

AZANHA, José M. P. Uma reflexão sobre a formação do professor da escola básica. In: . A formação do professor e outros escritos. São Paulo: Senac, 2006, p. 53-74.

BOURDIEU, Pierre; PASSERON, Jean-Claude. A reprodução: elementos para uma teoria do sistema de ensino. Tradução de Reynaldo Bairão. 2. ed. Rio de Janeiro: Francisco Alves, 1982.

CATANI, Denice B. Ensaios sobre a produção e circulação dos saberes pedagógicos. 167 f. Tese (Livre-Docência) - Faculdade de Educação da USP. São Paulo, 1994.

et al. História, memória e autobiografia na pesquisa educacional e na formação.

In: et al. (Org.). Docência, memória e gênero: estudos sobre formação. São Paulo: Escrituras, 1997, p. 13-48.

CHERVEL, André. História das disciplinas escolares: reflexões sobre um campo de pesquisa. Teoria \& Educação, Porto Alegre, n. 3, p. 177-229, 1990.

DEMARTINI, Zeila de B. F.; ANTUNES, Fátima F. Magistério primário: profissão masculina, carreira feminina. In: CAMPOS, Maria Christina S. de S.; SILVA, Vera Lúcia G. da. Feminização do magistério: vestígios do passado que marcam o presente. Bragança Paulista: EDUSF, 2002, p. 69-94.

FORQUIN, Jean-Claude. Saberes escolares, imperativos didáticos e dinâmicas sociais. Teoria \& Educação, Porto Alegre, n. 5, p. 28-49, 1992.

GIMENO SACRISTÁN, José. Consciência e acção sobre a prática como libertação profissional dos professores. In: NÓVOA, António. Profissão professor. Porto: Porto Editora, 1995, p. 63-92.

GOLLER, Gisele. A prática docente nas séries iniciais e seus determinantes. $167 \mathrm{f}$. Dissertação (Mestrado) - Programa de Estudos Pós-Graduados em Educação: História, Política e Sociedade da PUC/SP. São Paulo, 2002.

GOODSON, Ivor. Tornando-se uma matéria acadêmica: padrões de explicação e evolução. Teoria \& Educação, Porto Alegre, n. 3, p. 230-254, 1990.

JULIA, Dominique. 2001. A cultura escolar como objeto histórico. Revista Brasileira de História da Educação, n. 1, p. 9-43, jan./jun. 2001.

LOURO, Guacira. L. Gênero e magistério: identidade, história, representação. In: CATANI, D. B. et al. (Org.). Docência, memória e gênero: estudos sobre formação. São Paulo: Escrituras, 1997, p. 77-84. 
MARCELO GARCÍA, Carlos. Aprender a enseñar: um estúdio sobre el proceso de socializacion de professores principiantes. Madrid: Centro de Publicaciones del Ministério de Educación y Ciência: CIDE, 1991.

NÓVOA, António. Formação de professores e profissão docente. In: . Os professores e sua formação. Lisboa: Publicações Dom Quixote/Instituto de Inovação Educacional, 1995a, p. 15-33.

. O passado e o presente dos professores. In: . Profissão professor. Porto: Porto Editora, 1995b, p. 13-34.

PEREIRA, Luiz O magistério primário na sociedade de classes: contribuição ao estudo de uma ocupação na cidade de São Paulo. São Paulo: Livraria Pioneira, 1969.

POPKEWITZ, Thomas S. Profissionalização e formação de professores: algumas notas sobre a sua história, ideologia e potencial. In: NÓVOA, António. Os professores e sua formação. Lisboa: Publicações Dom Quixote/Instituto de Inovação Educacional, 1995, p. 35-50.

SAMPAIO, Maria das Mercês F.; MARIN, Alda J. Precarização do trabalho docente e seus efeitos sobre as práticas curriculares. Educação e Sociedade - Dossiê Globalização e Educação: precarização do trabalho docente - II, Campinas, v. 25, n. 89, p. 1203-1225, set./dez. 2004.

SANTOMÉ, Jurjo Torres. La práctica reflexiva y la comprensión de lo que acontece en las aulas. In: JAKSON, Ph. W. La vida en las aulas. Madrid: Morata, 1996, p. 11-26.

TARDIF, Maurice. Saberes docentes e formação profissional. Petrópolis: Vozes, 2002.

; RAYMOND, Danielle. Saberes, tempo e aprendizagem do trabalho no magistério. Educação e Sociedade, Campinas, v. 1, n. 73, p. 209-244, dez. 2000.

et al. Os professores face ao saber: esboço de uma problemática do saber docente. Teoria \& Educação, Porto Alegre, n. 4, p. 215-233, 1991.

VIÑAO-FRAGO, Antonio. Culturas escolares y reformas (sobre la naturaleza histórica de los sistemas e instituciones educativas). Teias, Rio de Janeiro: UERJ-FE, ano 1, n. 2, p. 116-134, jul./dez. 2000.

Texto recebido em 02 de fevereiro de 2010.

Texto aprovado em 09 de março de 2010. 